that may be, whether in the shape of a chemical compound, or in that of an animal or vegetable fungus. If the latter, perhaps they choose the intestinal glands as beds in which to develop themselves, something after the fashion of the flesh. worm.

Rhymney, Dec. 1867.

\section{TWO CASES OF LOSS OF THE EPIGLOTTIS.}

\section{BY HERMANN BEIGEL, M.D., M.R.C.P. LOND.,} PHYSICIAN TO THE MLITROPOLITAN FREE FOSPITAL.

CASEs in which the epiglottis or a portion of it has been lost in consequence of inflammatory affections of the larynx, followed by necrosis of the arythenoid or other cartilages, have not unfrequently been observed. The symptoms in such cases are generally very distressing, so as to necessitate even tracheotomy. If cure is effected, loss of speech or other func. tional defects of the larynx often remain.

But I have not been able to find records of cases in which destruction of the epiglottis has taken place in such a subacute manner that the patients have experienced neither pain nor loss of speech-in fact, that they were not at all aware of the deficiency. Both cases which I am about to describe were observed in tuberculous patients under my treatment at the Metropolitan Free Hospital.

CASE 1.- Elizabeth E-, aged forty-seven, married, but without issue, has been subject to tubercular disease for many years, cough, copious expectoration, and pain in the left side of the chest. The physical signs are those of an advanced stage of tuberculosis, particularly in the left lung. Pain in the throat, hoarseness, or any inconvenience in the larynx has never existed.

When examined by means of the laryngoscope, the larynx was found in a state represented in the accompanying woodcut. The false vocal cords rather thick and puffy; the true

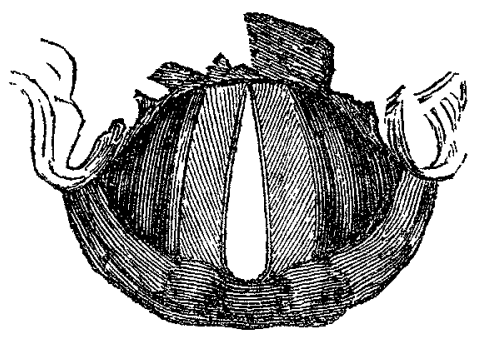

vocal cords almost normal; action of the muscles of the larynx energetic; the cartilages, with the exception of the epiglottis, intact. The epiglottis perfectly destroyed; only one larger and a few minute shreds of it left; the latter neither inflamed nor ulcerated, thus showing that the process of destruction has terminated long ago. The patient speaks with but a very slight touch of hoarseness, and has never experienced, during deglutition, any food going into the larynx instead of into the cesophagus.

The diagnosis could very easily be made, but there was no cause whatever for interfering with the larynx.

CASE 2. -The second case was that of a man thirty eight years of age, who had suffered for many years from hereditary tuberculosis. The state of the larynx was similar to that of the former patient. The destruction proceeded likewise without causing pain or any inconvenience to the patient; and the loss of the epiglottis was still more complete than in the former case, leaving only small granular remnants. But whilst the patient was under my care one such small granule became inflamed, enlarged to the size of a pea, and caused great pain, particularly when the patient was speaking or swallowing. When I viewed it in the laryngoscope it exhibited a yellow little spot at its most prominent part, indicating its containing pus. Consequently, under the guidance of the laryngeal mirror, I lanced it with an appropriate lancet, and, a drop of pus having escaped, the pain at once subsided; and after a few days the granule assumed a healthy appearance.

Finsbury-square, Mareh, 186 .

Her MaJesty has been pleased to present a copy of her new journal to the Kidderminster Infirmary,

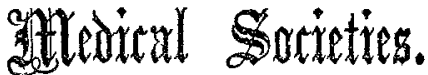

\author{
OBSTETRICAL SOCIETY OF LONDON. \\ WEDNESDAY, APRI, 1ST, 1868. \\ Dr. HALI DAVIS, PBESIDET,
}

Tt1E following gentlemen were elected Fellows :-Mr. Evan Llowellyn, Dr. Hope Robson, and Mr. Charles Case Smith, Dr. Philitips exhibited a specimen of Retro-Uterine Hrema. tocele.

Dr. Greenhalgh exhibited a specimen of Hypertrophied Nympha, removed by the ecraseur.

Dr. PhAYFarr related the particulars of a case in which a woman, suffering from carcinoma uteri, attended with much induration and rigidity of the cervix, had aborted of a dead foetus at the fifth month. The foetus, which had been extruded piecemeal, was exhibited.

The PRESTDENT exhibited the membranes of a twin ovum of a supposed ten veeks' gestation, which he had removed from a patient the subject of exhausting hamorrhage. The foetuses had been expelled eight days before, but their envelopes were retained, and were artherent to the anterior and posterior walls of the uterus respectively. They were extracted entire by the ovum forceps, and the hamorrhage had not recurred.

Dr. Protheros Surrer exhibited an instrument which he had devised to facilibate the extraction of hair-pins from the female bladder, and which in a recent case he had used with complete success.

A paper was read by Dr. Copenaty (of Norwich), "On some of the difficulties encountered in determining the exist. ence of Pregnancy." Five cases were given in detail, in all of which considerable difficulty had been at first felt in deciding on the queation of pregnancy, owing to the presence of some one or more abnormal conditions, but in all of which the author had been enabled to form a correct diagnosis mainly by detecting the "placental souffle" by anscultation. This sound, Dr. Copeman said, had never deceived him, and he expressed his surprise that in a recent work Dr. Hewitt had stated that no dependence whatever vas to be placed upon it as a sign of pregnancy. He, on the contrary, believed it to be one of the most valuable gigns of pregnancy, second only to that of the feetal heart, and the most dependable of all signs when the child was dead.

Dr. GraILY HEw IT thought the uterine souflle one of the signs of pregnancy which were not absolutely "reliable," and in this sense he had deprecated attention to it. In some of the cases now related, other observers had failed to hear it when it was evident to Dr. Copeman's more practised ear. He still believed it to be capable of simulation by other sounds, and in that sense of the word, "non-reliable."

ON PUEBPERAL FEVER IN THE BRITISH LYLNG-IN HOSPITAL WITH REMARKS ON THE TREATMENT OF PUERPERAL TEVER.

BV GRAILY HEWITT, M.D., F.R.C.P., PROFESSOR OF MIDWIFERY AT UNIVERSITY COLXEGE, YATE PHYGICIAN TO THE BRITISII LYING-IY FOSPITAL.

In this paper the author detailed his experience of puerperal fever in the British Lying-in Hospital; and laid before the Society certain views respecting the treatment of the disense there and elsewhere. The mortality in the hospital from all causes was in the first place attended to. The statistics adduced extended from 1849 to 1866 inclusive. Married women only are admitted. 'The hospital now in existence was first rsed for patients in 1849. Of the four principal wards, two had a cubic capacity of 6552 feet each; the two others of 5616 feet each. 'These wards were tolerably isolated, and ventilated by fireplaces and open windows. During the time the author held office there, the practice was to allot four patients, unless under extra pressure, to each ward. The in-patients were attended alternately by Dr. Murray and the author for periods of three months. During the seventeen years 1849-1866, the total deliveries were 2438 ; the total maternal deaths 25 . The percentage of deaths was, therefore, 1.02 from all causes. The causes of death were set down as follows:-Puerperal fever, or disease closely allied to it, 16 ; hæmorrhage, instrumental labours, chest affections complicating labour, and other diseases, 9. Of late years1863-1866-the number of deliveries had much increased, being nearly double those of previous years. In one year 